\title{
Cancer incidence in Jordan, 1996-2005
}

\author{
M. Al-Tarawneh, ' S. Khatib' ${ }^{2}$ and K. Arqub
}

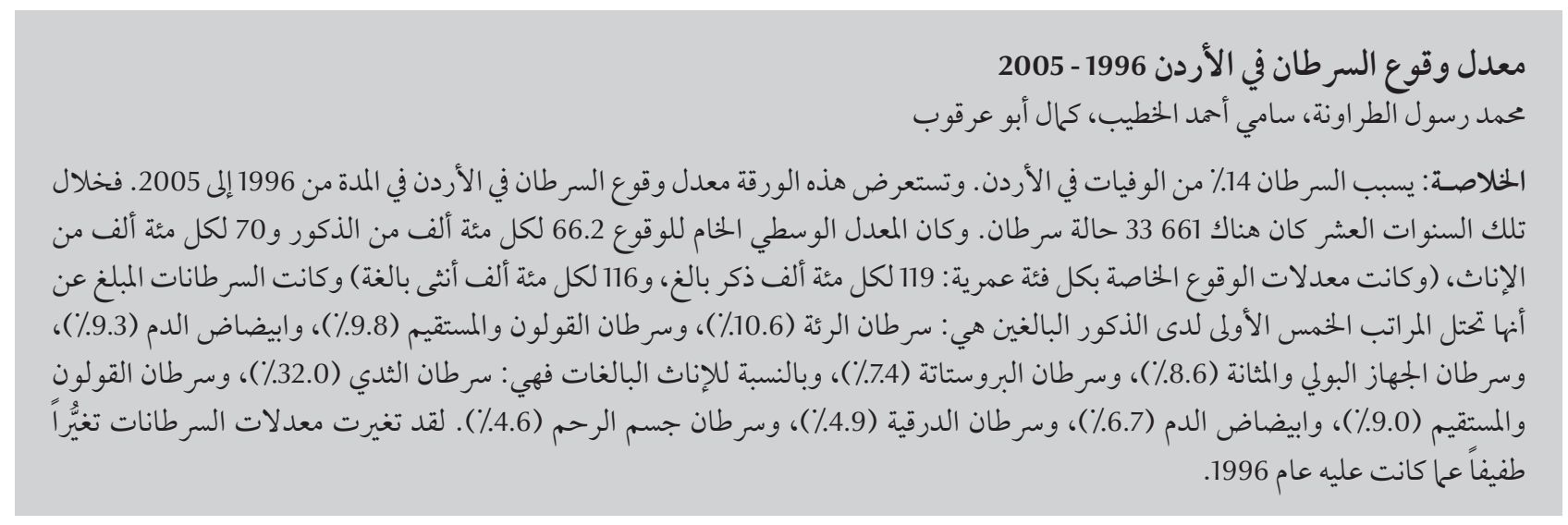

ABSTRACT Cancer causes $14 \%$ of all deaths in Jordan. This paper presents the incidence of cancer in Jordan from 1996 to 2005. Over the 10-year period there were 33661 cases of cancer. The average crude incidence rate was 66.2 per 100000 for males and 70.0 per 100000 for females (age-standardized rates: 119 per 100000 adult males and 116 per 100000 adult females). The 5 most frequently reported cancers among adult males were: lung (10.6\%), colorectal (9.8\%), leukaemia (9.3\%), urinary and bladder (8.6\%) and prostate (7.4\%). For adult females these were: breast (32.0\%), colorectal (9.0\%), leukaemia (6.7\%), thyroid (4.9\%) and corpus uteri (4.6\%). Cancer rates have changed little since 1996.

\section{Incidence du cancer en Jordanie entre 1996 et 2005}

RÉSUMÉ Le cancer est à l'origine de $14 \%$ des décès en Jordanie. Cet article présente l'incidence du cancer en Jordanie entre 1996 et 2005. Au cours de la période de 10 ans sur laquelle a porté l'étude, 33661 cas de cancer ont été détectés. Le taux d'incidence brut moyen était de 66,2 pour 100000 chez les hommes et de 70,0 pour 100000 chez les femmes (taux d'incidence standardisé en fonction de l'âge : 119 pour 100000 chez les hommes et 116 pour 100000 chez les femmes). Les cinq cancers les plus fréquents chez les hommes étaient le cancer du poumon (10,6\%), le cancer colorectal (9,8\%), la leucémie (9,3\%), le cancer urinaire et de la vessie $(8,6 \%)$ et le cancer de la prostate $(7,4 \%)$. Chez les femmes, les cinq cancers les plus fréquemment observés étaient le cancer du sein (32,0 \%), le cancer colorectal (9,0\%), la leucémie (6,7\%), le cancer de la thyrö̈de (4,9\%) et le cancer du corps utérin (4,6\%). Les taux de cancer ont peu évolué depuis 1996.

'National Cancer Registry, Amman, Jordan (Correspondence to M. Al-Tarawneh: amman992001@yahoo.com). ${ }^{2}$ King Hussein Institute for Biotechnology and Cancer, Amman, Jordan.

Received: 19/11/08; accepted: 08/01/09 


\section{Introduction}

Cancer is a major public health problem. In 2005, 7.6 million people died of cancer out of 58 million deaths worldwide [1]. More than $70 \%$ of all cancer deaths occur in low- and middle-income countries, where the resources available for prevention, diagnosis and treatment of cancer are limited or nonexistent. The World Health Organization (WHO) estimates that there will be 20 million new cases and 12 million deaths from cancer alone by the year 2020 [2].

In a study comparing 4 member countries of the Middle East Cancer Consortium (Cyprus, Egypt, Israel and Jordan) with the Surveillance, Epidemiology and End Results (SEER) survey in the United States of America (USA), the overall incidence of cancer was substantially higher in the USA and in Israeli Jews than in other Middle East populations [3]. Egyptians and Israeli non-Jews (who are mostly Arabs) had intermediate rates, while the rates in Jordanians were the lowest. A high incidence of breast cancer was found in Israeli Jews compared with Arab populations and these differences provide an example of the potential role of lifestyle and genetic factors in the etiology of breast cancer [3].

The implementation of different strategies for the control and prevention of many communicable diseases of childhood, along with rapid improvements in socioeconomic status and improvements in health services in Jordan have led to the emergence of noncommunicable diseases as the dominant source of ill health. Cancer is the second leading cause of death in the country.

As cancer incidence rates have not been described in a comprehensive manner in Jordan we present here epidemiological data on cancer cases reported to the national cancer registry during the 10-year period 1996-2005.

\section{Methods}

\section{Background-Jordan cancer registry}

The Jordan cancer registry (JCR) was established in 1996 as a populationbased registry to collect data from all relevant health facilities: public, Royal Medical Services, university and private as well as pathology laboratories. The registry includes all malignant and in situ malignancies diagnosed since January 1996 in people resident in Jordan.

The JCR employs a combination of active and passive methods of casefinding. Active collection involves registry personnel visiting different facilities on a regular basis and abstracting data onto cancer registry forms. Passive reporting involves trained personnel in the different hospitals abstracting cancer data from patients' files, completing the notification forms and forwarding them to the registry. Figure 1 shows the cancer statistics for Jordan going back to 1980. The number of cases registered approximately doubled in 1996 when the JCR was transformed from a hospital-based to a population-based registry.

All cancer cases are coded using the 3rd revision of the International classification of diseases for oncology (ICDO-3) [4]. CanReg4 software is used for data entry [5]. Duplicate entries are avoided by checking by name, age, diagnosis and place of residence. JCR relies for the most part on histology or cytology reports when defining incident cases. Data obtained from the pathology laboratories for all cancer cases are compared with those received from the hospitals. Missing data are sought from the respective institutions. The validity of the data is verified through internal quality checks, external checks and computer checks.

\section{Data collection}

For the current study we extracted and analysed the data on cancer cases registered from January 1996 to December 2005 using a team of trained medical coders who checked the data against the information originally registered.

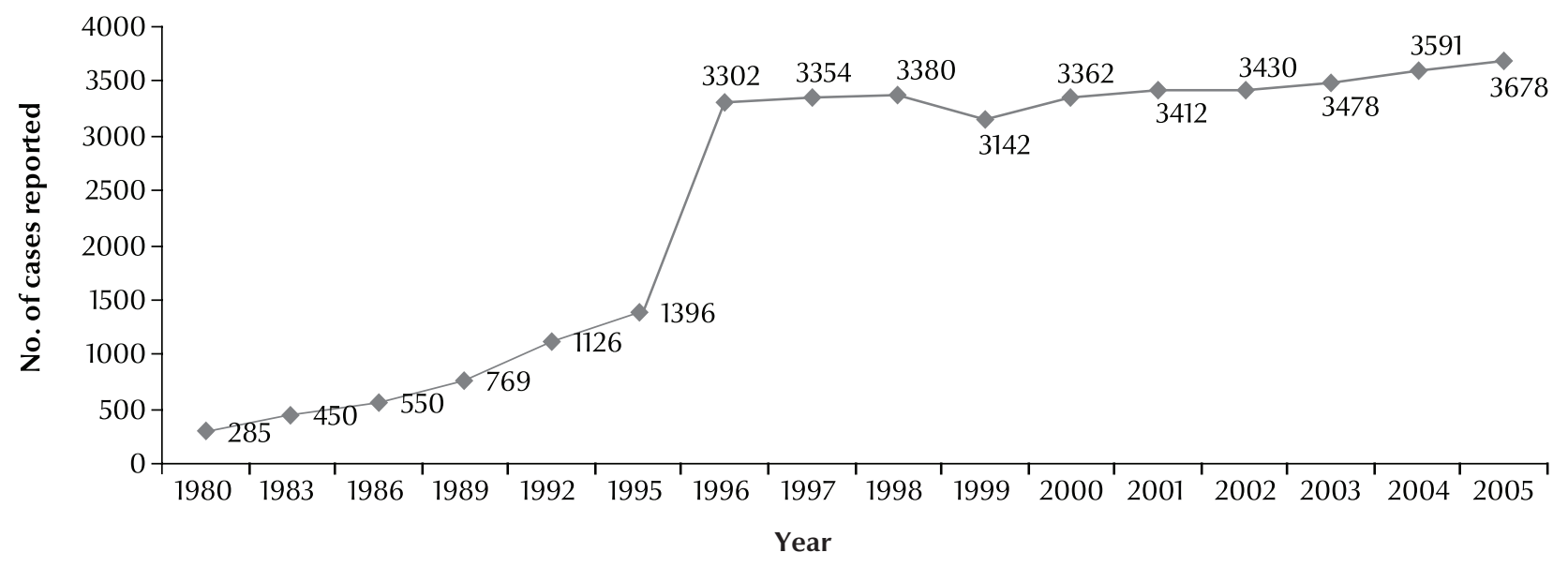

Figure 1 Trend of number of cancer cases, all sites, in the Jordan cancer registry, 1980-2005 
To assess the accuracy of the data we recaptured cases from files and case notes from hospitals and compared it with other data sources. Also visual editing and automated software applications were applied to improve the accuracy of the data and to eliminate duplicate cases. Accuracy was generally high for demographic, diagnostic and treatment details, but less so for grade of differentiation, staging variables and dates of treatment.

Although the JCR collects data on all cancer cases occurring in Jordan, the present analysis was restricted to people of Jordanian nationality in order to ensure completeness of data and avoid the difficulty of estimating the age-adjusted rates for non-Jordanian populations.

\section{Analysis}

Jordan had a population in 2000-01 of 5.2 million, approximately $38 \%$ of whom were under the age of 15 years and only $3.6 \%$ over the age of 65 years.
The average crude incidence rates were calculated using the average population for the index years 2000-01. The world standard population [6] was used to obtain age- standardized incidence rates (ASRs). Epi-Info, version 6, was used for statistical analysis.

\section{Results}

Between January 1996 and December 2005, 33661 cases of cancer in Jordanians were reported to the JCR: 16981 in males and 16680 in females, a male to female ratio of 1:1.2.

\section{Crude incidence rates}

The highest crude incidence rate for males was 74.7 per 100000 in 1996 and for females 75.2 per 100000 in 1997. The highest annual rates were noticed during the early years of establishing the registry at a time when data collection was most active; subsequently the rates stabilized (Figure 2).

The average annual crude incidence rate was 66.2 per 100000 population for males and 70.0 per 100000 population for females. When analysed by governorate the highest average crude incidence was in Amman, the capital, at 101.4 per 100000 population, followed by Irbid (53.3) (Figure 3). The lowest average crude incidence was in Mafraq governorate (20.1 per 100000 population).

In Jordan lung cancer was the leading cancer among males (10.6\%), followed by colorectal (9.8\%), leukaemia (9.3\%), urinary and bladder $(8.6 \%)$ and prostate cancer $(7.4 \%)$ (Table 1$)$. Among females, breast cancer was the most common malignancy (32.0\%), followed by colorectal $(9.0 \%)$, leukaemia $(6.7 \%)$, thyroid $(4.9 \%)$ and corpus uteri cancer (4.6\%) (Table 2).

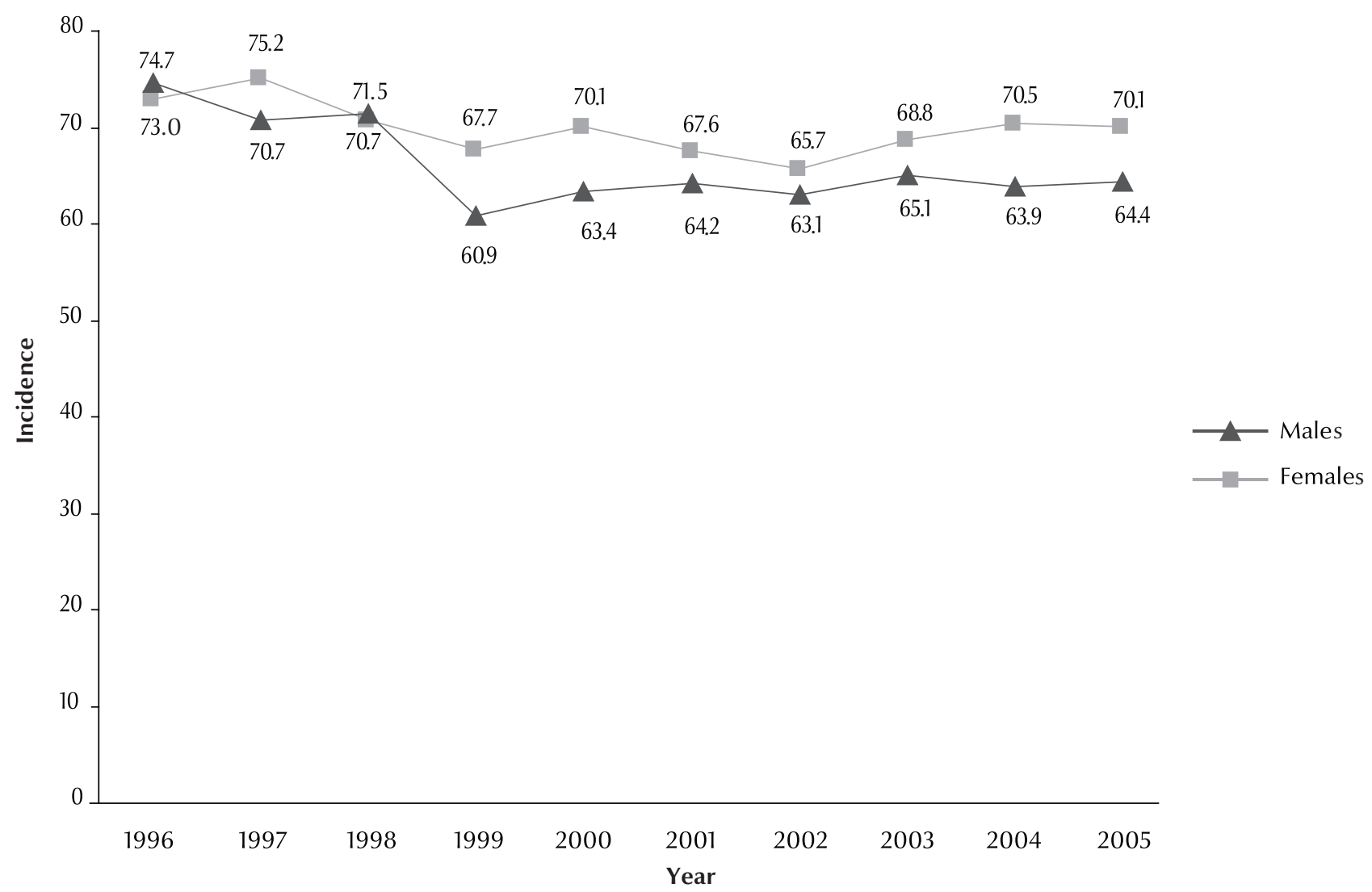




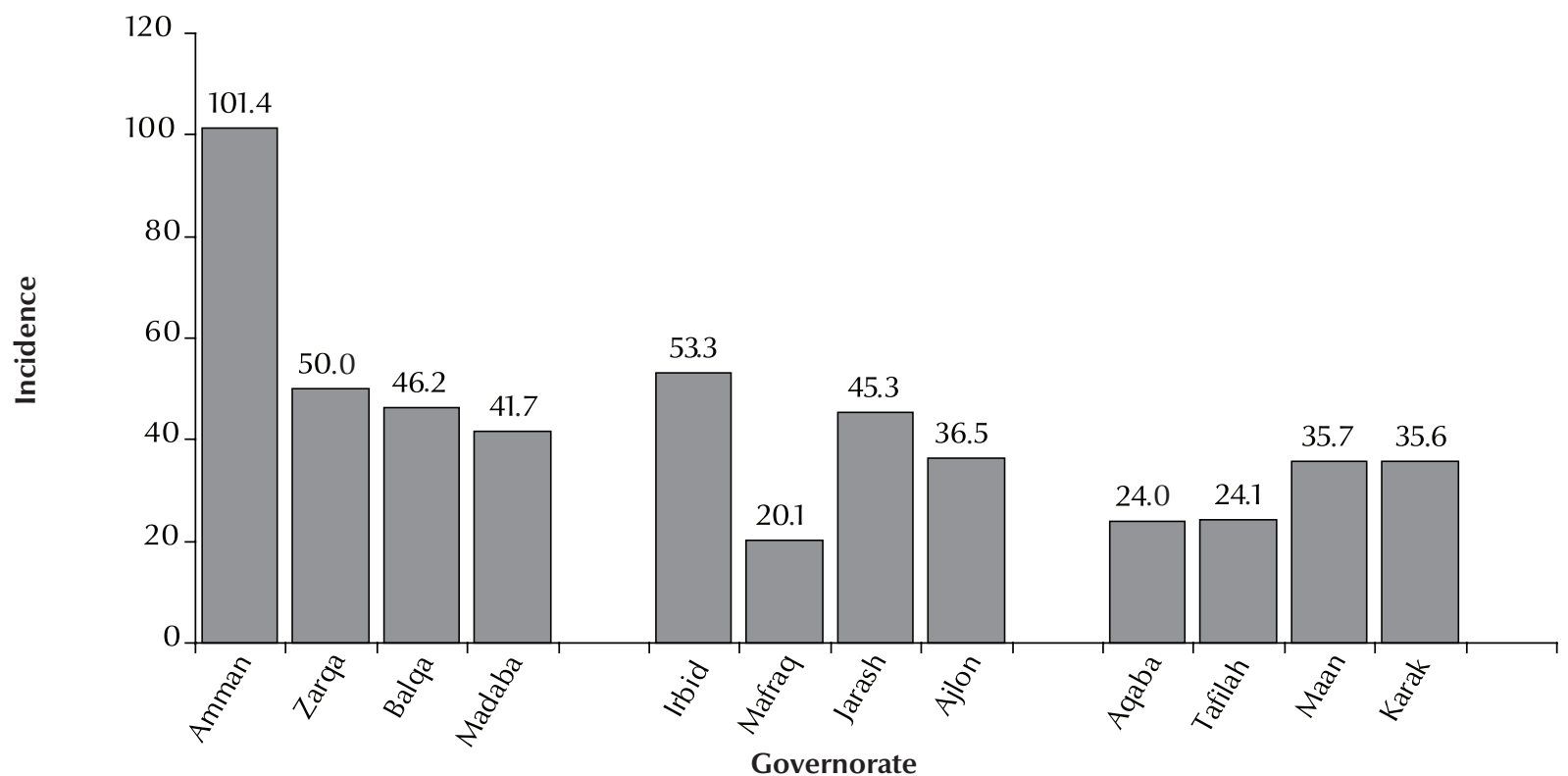

Figure 3 Average crude incidence of cancer (per 100000 population), all sites, by governorate, Jordan, 1996-2005

\section{Age-specific incidence rates}

Figure 4 shows the ASRs for all cancers in males and females. The overall average ASRs for all cancers were 119 per 100000 adult males and 116 per 100000 adult females (Table 3). The median age at diagnosis was 56 years for males and 53 years for females. By site of cancer the ASRs per 100000 population for lung cancer were 16.3 and 3.6 per 100000 in males and females respectively and for colorectal cancer were 20.1 and 14.6 per 100000 respectively. The ASR for breast cancer was 39.9 per 100000 females.

The incidence of lung cancer in Jordan rose sharply with age, with a first peak of increase of ASR in the age group 40-49 years for both males and females, which continued to rise steadily among males to a peak in the age group 70-74 years (Figure 5).

Colorectal cancer was rare under 40 years of age, after which the rates began to rise steadily. By the age of $40-59$ years, the rates were 18.7 and 24.3 per 100000 for males and females respectively (Figure 6).

\section{Discussion}

Cancer is usually considered a disease of industrialized countries. However, increases in life expectancy in most developing countries, even in the least developed [1], together with recent changes in lifestyle, have led to an epidemic of cancer in developing countries. With current trends it is estimated that by the year $202070 \%$ of the new cases of cancer will be diagnosed in people living in developing countries [12].

Since the 1970s Jordan has witnessed a transition of morbidity and mortality from communicable diseases of childhood to noncommunicable diseases in adults. This is partly due to improvements of the socioeconomic status in the country, the expansion of health services and the strengthening of the primary health care system. With the successful control of most communicable diseases of childhood, the leading causes of mortality and morbidity have become cardiovascular diseases, cancer and injuries.

The ASR per 100000 males in Jordan is similar to the rates reported in some other Arab countries such as Kuwait [7], Bahrain [7] and Tunisia [10]. The ASR per 100000 females in

\begin{tabular}{|c|c|c|c|}
\hline \multicolumn{4}{|c|}{$\begin{array}{l}\text { Table } 1 \text { Frequency of the } 10 \text { most common cancers among Jordanian males, } \\
\text { 1996-2005 }\end{array}$} \\
\hline Rank & Cancer site & No. $(n=16981)$ & $\%$ \\
\hline 1 & Lung & 1836 & 10.6 \\
\hline 2 & Colorectal & 1685 & 9.8 \\
\hline 3 & Leukaemia & 1602 & 9.3 \\
\hline 4 & Urinary \& bladder & 1481 & 8.6 \\
\hline 5 & Prostate & 1274 & 7.4 \\
\hline 6 & Non melanoma skin & 1106 & 6.4 \\
\hline 7 & Brain \& central nervous system & 848 & 5.2 \\
\hline 8 & Non-Hodgkin lymphoma & 824 & 4.7 \\
\hline 9 & Stomach & 814 & 4.7 \\
\hline 10 & Hodgkin disease & 582 & 3.3 \\
\hline
\end{tabular}




\begin{tabular}{|c|c|c|c|}
\hline Rank & Cancer site & No. $(n=16680)$ & $\%$ \\
\hline 1 & Breast & 5373 & 32.0 \\
\hline 2 & Colorectal & 1517 & 9.0 \\
\hline 3 & Leukaemia & 1132 & 6.7 \\
\hline 4 & Thyroid & 829 & 4.9 \\
\hline 5 & Corpus uteri & 758 & 4.6 \\
\hline 6 & Non melanoma skin & 751 & 4.5 \\
\hline 7 & Brain \& central nervous system & 606 & 3.6 \\
\hline 8 & Ovary & 605 & 3.3 \\
\hline 9 & Non-Hodgkin lymphoma & 545 & 3.3 \\
\hline 10 & Stomach & 461 & 2.7 \\
\hline
\end{tabular}

Jordan is similar to rates among females in Kuwait [7]. comparison with other countries of the REgion is shown in Table 3. The ASRs for all cancers in Jordan, in males and females, were substantially lower than those in the USA (162.7 and 110.4 respectively) and the United Kingdom (173.7 and 121.3 respectively) [13].

These differences between Jordan and other countries, particularly industrialized countries, can be attributed to many factors, especially differences in lifestyle, which have become more apparent only in the past 2 decades. These include smoking and physical inactivity; in the 2005 behavioural risk factor survey $51 \%$ of Jordanian males and $7 \%$ of females reported being smokers [14]. Fat intake is relatively low compared with industrialized societies and the traditional diet of Jordanians consists of a moderate intake of fruits and vegetables rather than meat [14]. The recent demographic changes in Jordan - characterized by low infant mortality (22 per 1000 live births), a high total fertility rate (3.7) and life expectancy comparable to that in the developed world (71.5 years for both sexes) —indicate that the elderly population will increase in the future [15].

Breast cancer is the most common cancer in women, with 900000 new cases occurring annually worldwide $[2,12]$ and is becoming ever more significant in many developing countries $[16,17]$. It has been found to be a majorcause of death from cancer, second to lung cancer, in Jordan. Our data indicate that it is the dominant cancer among Jordanian women, with approximately 500-550 new cases occurring annually. The ASR was 39.9 per 100000 females, higher than that of Saudi Arabia, Oman, Algeria, Bahrain and Tunisia (13.9, 14.9, 16.7, 28.6 and 34.6 respectively), but lower than that in Lebanon, Egypt, Kuwait and the USA SEER population (76.1, 49.6, 46 and 97.3 respectively) $[3,18]$. Breast cancer arises from a multifactorial process and can be viewed as a disease predominantly influenced by risk factors related to lifestyle, as only about $15 \%$ of all breast cancer cases can be attributed to familial and genetic influences [19]. Differences in the prevalence of exposure to these lifestyle and genetic risk factors among women from different countries in the Middle East are probably responsible for the

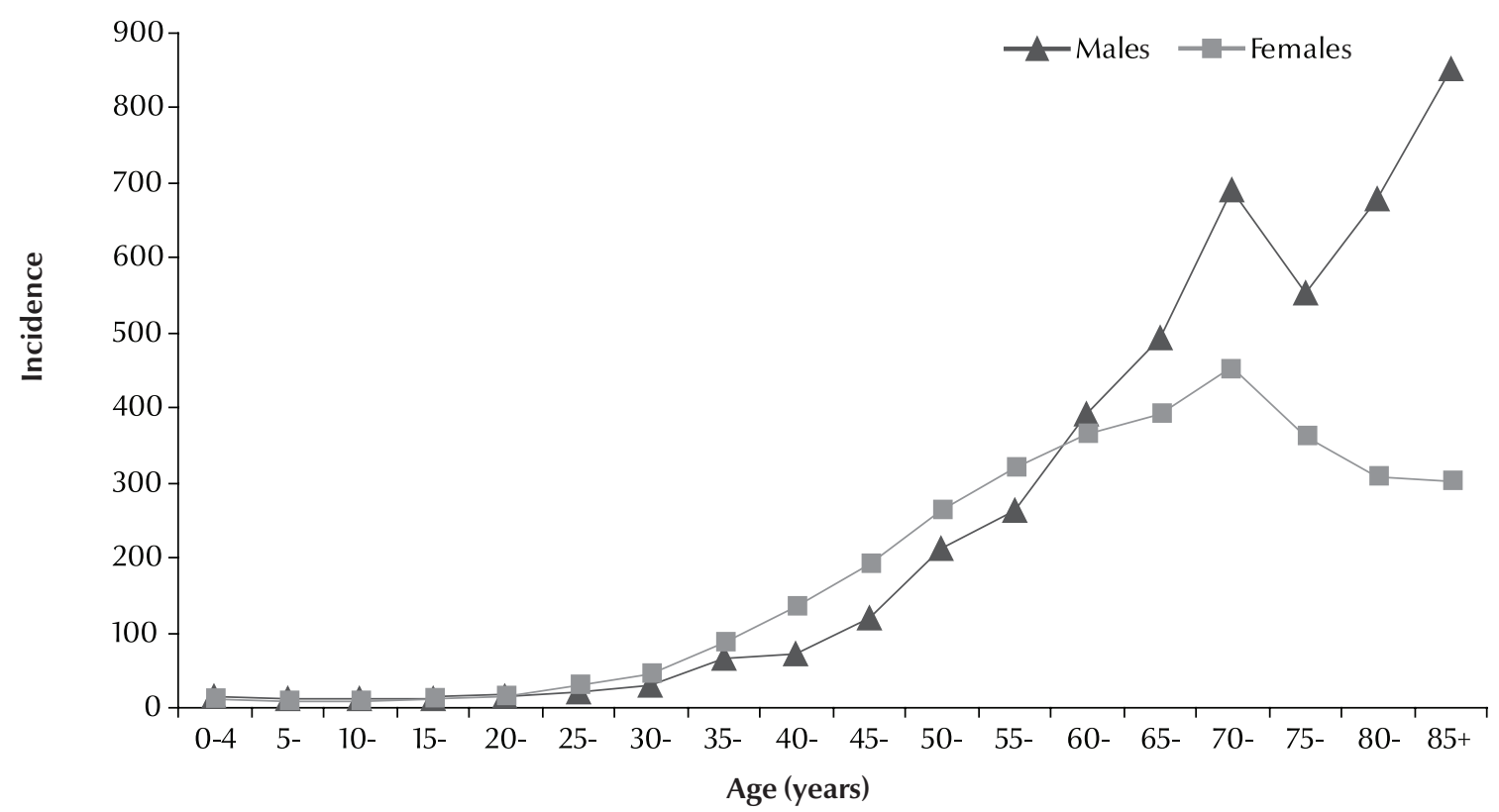

Figure 4 Average age-specific-incidence rate of cancer (per 100000 population), all sites, Jordan, 1996-2005 


\begin{tabular}{lccc}
\hline \multicolumn{3}{l}{$\begin{array}{c}\text { Table } 3 \text { Age-specific incidence rates (ASR) for all cancers in Jordan compared with } \\
\text { other countries of the Eastern Mediterranean Region }\end{array}$} \\
\hline Country & Source & All cancers ASR per 100 000 & population \\
& & Males & Females \\
Jordan & Current study & 119 & 116 \\
Bahrain & {$[7]$} & 118 & 108 \\
Egypt & {$[8]$} & 152 & 136 \\
Kuwait & {$[7]$} & 121 & 120 \\
Lebanon & {$[9]$} & 169 & 176 \\
Morocco & {$[10]$} & 96 & 87 \\
Oman & {$[7]$} & 110 & 93 \\
Qatar & {$[7]$} & 180 & 152 \\
Saudi Arabia & {$[7]$} & 68 & 66 \\
Sudan & {$[10]$} & 102 & 95 \\
Syrian Arab Republic & {$[11]$} & 180 & 167 \\
Tunisia & {[]} & 114 & 78 \\
United Arab Emirates & {$[7]$} & 78 & 70 \\
\hline
\end{tabular}

variability in breast cancer incidence seen between countries in this area $[20,21]$. Time trends in the prevalence of the lifestyle risk factors can be directly correlated with time trends in breast cancer incidence.

Most known risk factors for breast cancer can be linked to the hazardous effects of hormone exposure, although other risk factors such as exposure to ionizing radiation are also relevant in some populations [22,23]. Increasing parity and early age at first parity are protective against breast cancer development [24]. Women's breast cancer risk reduces by $4 \%$ for every 12 months of breastfeeding [25]. There is clear evidence in the general population that obesity is associated with a significantly higher risk of breast cancer [26]. History of benign breast disease is also related to increased risk of breast cancer. The risk, however, is mostly restricted to women who have undergone biopsies and especially those in whom atypical hyperplasia was found in such biopsies [27]. Most studies have focused on the influence on breast cancer incidence of modern lifestyles such as a high cholesterol intake, alcohol consumption and smoking. Dietary fat has been the most investigated food constituent studied in this regard and it is currently believed that a high-fat diet is related to the risk of breast cancer among women with no history of benign breast disease [28]. Active and passive smoking have recently been shown to be related to breast cancer risk $[29,30]$.

Worldwide, colorectal cancer represents $9.4 \%$ of all incident cancers in men and $10.1 \%$ in women. In Jordan colorectal cancer was the second most common cancer among both males and females, while globally the ASR of colorectal cancer in 2002 was 20.1 per 100000 males and 14.6 per 100000 females. There are notable differences in colorectal cancer incidences in more developed versus less developed countries. In the developed parts of the world, the ASR per 100000 is 40.0 in males and 26.6 in females; in less developed areas the rates are 10.2 and 7.7 respectively. In Jordan, the ASR was 11.5 and 11.2 for males and females

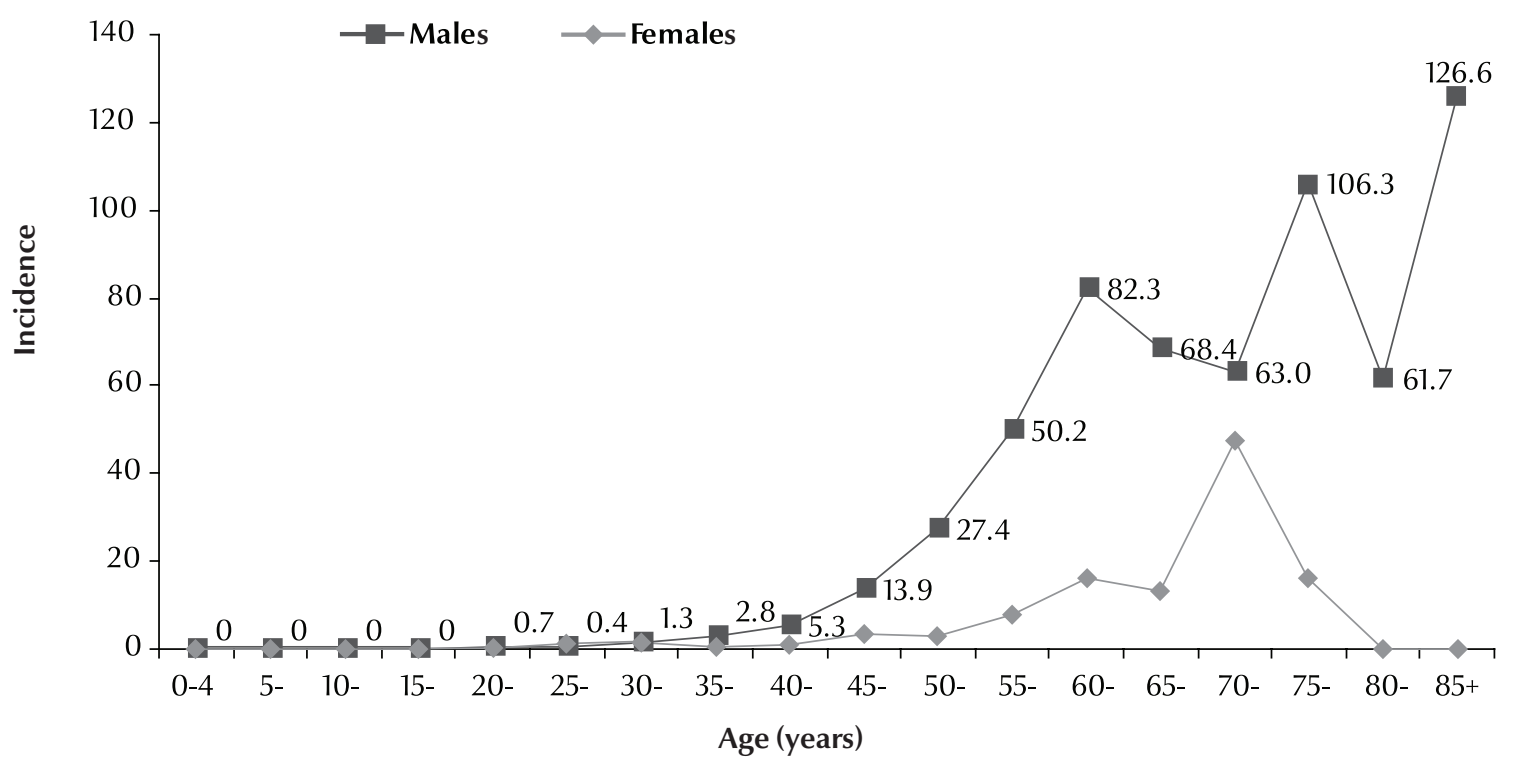

Figure 5 Average age-specific-incidence rate (per 100000 population), lung cancer, Jordan, 1996-2005 


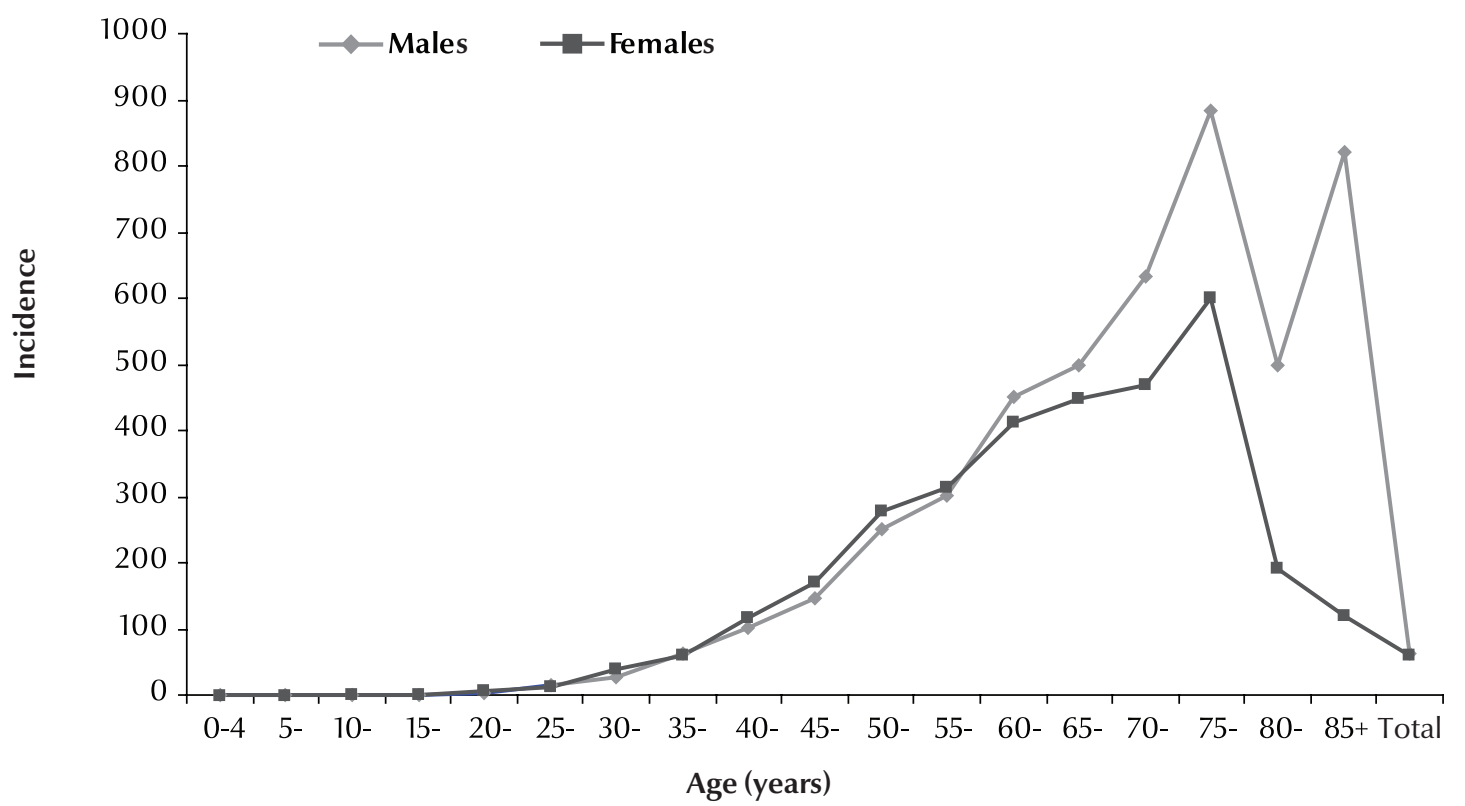

Figure 6 Average age-specific-incidence rate (per 100000 population), colorectal cancer, Jordan, 1996-2005

respectively. The highest ASR in males was observed in Australia/New Zealand (48.2), followed by North America (44.4) and Western Europe (42.9). At the other end of the scale, the rates in South-Central Asia (4.7) and Central Africa (2.3) were the lowest [10].

In Jordan colorectal cancer was rare under 40 years of age, and the rates began to rise steadily after this age. By the age of 40-59 years, the Jordanian population had rates per 100000 of 18.7 and 24.3 for males and females respectively. These rates were relatively close to those among Egyptians but lower than the rate of the US SEER population (43.3 and 32.8 for males and females respectively) [3]. In Jordanians, the rates rose by about 20\% for each 5-year period between the ages of 50 and 75 years. Evidence from epidemiological studies seems to show consistently that intake of dietary fat and meat is linked to colorectal cancer. Consumption of animal fat was found to be associated with increased risk of colon cancer [31].

Throughout the world, lung cancer is the most commonly diagnosed cancer and causes more deaths than any other cancer [10]. In Jordan, 14.7\% of cancer deaths are due to lung cancer [3]. International variations in the incidence are striking, with ASRs < 10 per 100000 in parts of Africa, China, and South America and > 100 per 100000 in the USA [18]. In Jordan the ASR of lung cancer per 100000 was 16.3 per 100000 in males, which is similar to that among Egyptians and Kuwaitis (14.0 and 11.3 respectively), but lower than that among Tunisians, Bahrainis and Qataris (27.8, 33.5 and 36.3 respectively) [18]. As expected, lung cancer ASRs increased with age from the youngest age group (<50 years of age) to the oldest (age $70+$ years).

The overall ASR of lung cancer in the Jordan population was much lower than in the USA SEER population [3], between one-third and one-quarter of the US SEER rates. In Jordan the lung cancer ASR in females was lower than in males (3.6 versus 16.3 per 100000 population). Rates of cancer of thelung/ bronchus are similar among Israeli Jews and non-Jews and about twice as high as in Jordanians [32]. Worldwide statistics show that the lung cancer ASRs per 100000 for males in other Arab countries, such as Algeria (17.1) and Kuwait
(11.3), were relatively close to those in Jordan (16.3), while the rate among Jordanian males was lower than that in Tunisia, Bahrain and Qatar (27.8, 33.5 and 36.3 respectively) [18]. However, the rate per 100000 was lower than in Western countries such as Canada (59.0), Ireland (42.3) and the USA (61.9). All the female populations of the EMR including Jordan, display rates far lower than the USA SEER female population [3]. The ASRs per 100000 females in Algerians (1.9) and Omanis (2.6) [33] were somewhat lower than in Jordanians (3.5) and Egyptians (3.6), although Kuwaitis (4.1) had a slightly higher rate.

By far the most important risk factor in the development of lung cancer is tobacco use. Smoking more than 20 cigarettes per day has been shown to confer a 15- to 25-fold higher risk of lung cancer relative to nonsmokers [34]. Both the duration and intensity of cigarette smoking increases the risk, as does the tar content and the lack of a filter [35]. The risk decreases with time after cessation of smoking, with longterm exsmokers approaching but not reaching the risk of nonsmokers [36]. Other types of tobacco smoking, such 
as pipe, cigar and waterpipe smoking, are also linked to lung cancer, although the relative risks are not as high as for cigarette smoking. Exposure to passive smoking or environmental tobacco smoke is also related to an increased risk of lung cancer, although the relative risk is much lower than in active smokers. Worldwide, the incidence of lung cancer among males is much higher than among females, due primarily to the lower prevalence of smoking among females. Several other risk factors for lung cancer have been identified. Occupational exposures that increase the risk of lung cancer include asbestos, which also causes an increase in the risk of mesothelioma. Asbestos exposure and cigarette smoking act synergistically, together raising the risk of lung cancer multiplicatively [37].

\section{Conclusion}

This is the first comprehensive report on cancer incidence in Jordan since the JCR was established in 1996 and expanded its work to cover the entire country. The study was based on data from 33661 cases diagnosed during a 10-year period. At present, the actual burden of cancer in Jordan remains acceptable, with less than 5000 cases per year. However, as the country undergoes demographic and socioeconomic changes, the burden of cancer may increase in future decades. The pattern of cancer among males and females in Jordan is consistent with the Regional picture, with breast cancer being the most common cancer among females and lung cancer the dominant cancer among males throughout the study period.

\section{References}

1. World health report 2005. Make every mother and child count Geneva, World Health Organization, 2005.

2. Parkin DM et al. Global cancer statistics, 2002. CA: a Cancer Journal for Clinicians, 2005, 55:74-108.

3. Freedman $\mathrm{L}$ et al. Cancer incidence in four member countries (Cyprus, Egypt, Israel, and Jordan) of the Middle East Cancer Consortium (MECC) compared with US SEER. (MECC Monograph). Bethesda, Maryland, National Cancer Institute, 2006 (NIH Publication No.06-5873).

4. Fritz A et al. International classification of diseases for oncology, 3rd ed. Geneva, World Health Organization, 2000.

5. CanReg4 manual. Lyon, International Agency for Research on Cancer, 2001.

6. Plummer M, Parkin D, et al. Cancer incidence on five continents Lyon, International Agency for Research on Cancer, 1997:6668 (IARC Scientific Publications, No. 143).

7. Cancer incidence report of Gulf Cooperation Council States. Riyadh, Gulf Center for Cancer Registration, 2003.

8. Cancer incidence in Egypt, Gharbiah. Triennial report of 20002002. Gharbiah population-based registry. Cairo, Ministry of Health and Population, 2007.

9. Salim M, Adib, Daniel J. Cancer in Lebanon. Beirut, Ministry of Health, National Cancer Registry, 2003.

10. Ferlay J et al. GLOBOCAN 2002: cancer incidence. Mortality and prevalence worldwide. IARC cancer base no. 5, version 2.0. Lyon, International Agency for Research on Cancer Press, 2004.

11. Cancer incidence report. National Cancer Registry. Damascus, Ministry of Health of the Syrian Arab Republic, 2006.

12. Stewart BW, Kleihues P. World cancer report. Geneva, World Health Organization/Lyon, International Agency for Research on Cancer, 2003.

13. Landis S, Murray T, Bolden S. Cancer statistics. CA: a cancer journal for clinicians, 1998, 48:6-29.

14. Behavioral risk factors survey. Amman, Ministry of Health of Jordan, 2005.

15. Annual statistical book. Amman, Ministry of Health of Jordan, 2005.

16. Parker SL et al. Cancer statistics, 1996. CA: a Cancer Journal for Clinicians, 1996, 46:5-27.
17. Veronesi U, Goldhirsch A, Yamold J. Breast cancer. In: Peckham M, Pinedo HM, Veronesi U, eds. Oxford textbook of oncology. Oxford, Oxford Medical Publications, 1995:1243-1289.

18. Parkin DM, Whelan SL, et al. Cancer incidence in five continents, volume VIII. IARC Scientific Publication, No. 155. Lyon, International Agency for Research on Cancer, 2002.

19. Martin AM, Weber BL. Genetic and hormonal risk factors in breast cancer. Journal of the National Cancer Institute, 2000, 92:1126-1135.

20. Chlebowski RT et al. Ethnicity and breast cancer: factors influencing differences in incidence and outcome. Journal of the National Cancer Institute, 2005, 97:439-448.

21. Bernstein $L$ et al. Ethnicity-related variation in breast cancer risk factors. Cancer, 2003, 97:222-229.

22. Ronckers CM, Erdmann CA, Land CE. Radiation and breast cancer: a review of current evidence. Breast Cancer Research, 2005, 7:21-32.

23. Carmichael A, Sami AS, Dixon JM. Breast cancer risk among the survivors of atomic bomb and patients exposed to therapeutic ionizing radiation. European Journal of Surgical Oncology, 2003, 29:475-479.

24. Antoniou $\mathrm{AC}$ et al. parity and breast cancer risk among BRCA1 and BRCA2 mutation cancers. Breast Cancer Research, 2006, 8(6):R72.

25. Breast cancer and breast feeding: collaborative reanalysis of individual data from 47 epidemiological studies in 30 countries. Lancet, 2002, 360:187-195.

26. Friedenreich CM. Review of anthropometric factors and breast cancer risk. European Journal of Cancer Prevention, 2001:10(1):15-32.

27. Vogel VG. Atypia in the assessment of breast cancer risk: implications for management. Diagnostic Cytopathology, 2004, 30:151-157.

28. Velie $\mathrm{E}$ et al A. Dietary fat, fat subtypes, and breast cancer in postmenopausal women: a prospective cohort study. Journal of the National Cancer Institute, 2000, 92:833-839.

29. Collaborative Group on Hormonal Factors in Breast Cancer. Alcohol, tobacco and breast cancer-collaborative reanalysis of individual data from 53 epidemiological studies, including 58,515 women with breast cancer and 95,067 women without the disease. British Journal of Cancer, 2002, 87:1234-1245. 
30. Reynolds P et al. Active smoking, household passive smoking, and breast cancer: evidence from the California Teachers Study. Journal of the National Cancer Institute, 2004, 96:29-37.

31. Boyle P, Langman JS. ABC of colorectal cancer: Epidemiology. Student BMJ, 2000, 8:435-476.

32. Freedman $L$ et al. A comparison of population-based cancer incidence rates in Israel and Jordan. European Journal of Cancer Prevention, 2003, 12:359-365.

33. Blot WJ, Fraumeni JF, eds. Cancer of the lung and pleura. Cancer epidemiology and prevention, 2nd ed. New York, Oxford University Press, 1996:637-665.
34. Hammond EC. Smoking in relation to the death rates of one million men and women. National Cancer Institute Monograph, 1966, 19:127-204.

35. Lubin $\mathrm{JH}$ et al. Patterns of lung cancer risk according to type of cigarette smoked. International Journal of Cancer, 1984, 33:569-576.

36. Tobacco smoking: monographs on the evaluation of carcinogenic risk of chemicals to man, volume 38. Lyon, International Agency for Research on Cancer, 1986.

37. Berry G, Newhouse ML, Antonis P. Combined effect of asbestos and smoking on mortality from lung cancer and mesothelioma in factory workers. British Journal of Industrial Medicine, 1985, 42:12-18.

\section{Towards a strategy for cancer control in the Eastern Mediterranean Region}

Although the incidence of cancer is still well below that in developed countries, the Eastern Mediterranean Region is expected to experience the highest increase among all WHO regions in the coming two decades. The increasing trend can be attributed to many factors including population ageing and exposure to risk factors such as smoking, unhealthy diet, etc. It is estimated that $40 \%$ of cancers can be prevented by risk factor modification; prevention therefore offers the greatest public health potential and the most cost-effective long-term approach for cancer control.

Towards a strategy for cancer control in the Eastern Mediterranean Region was developed in response to the increasing burden of cancer and the need for coordinated action in this regard. This publication reflects a shared commitment to reducing the incidence of cancer and improving the quality of life of those who develop cancer. .

Full text is available at: http://www.emro.who.int/dsaf/dsa1002.pdf 